This combination of laboratory investigation with field observation is natural history at its best.

The book is well illustrated with splendid photographs in both colour and black and white as well as by many clear, helpful diagrams.

JOHN CLEGG

\title{
Man and Environment, by Robert Arvill. Penguin Books, 8s. $6 \mathrm{~d}$.
}

This book sets out to survey and evaluate the impact of man and modern technology on the varied components of our physical and biological environment, of which wildlife is treated as an integral component. Although primarily concerned with Britain, extensive use is made of experience from other parts of the world. The first part is concerned with a survey of the country's environmental resources and an appraisal of the impact of current and future expanding and competing demands. By bringing together an impressive amount of scattered and often inaccessible information, the author has achieved a remarkably comprehensive survey that will be indispensable to all concerned with any aspect of land use and conservation in Britain. In the latter half of the book, he sets out his views on the steps necessary to achieve continuous improvement in the quality of the environment. In many ways, this is the most interesting part. In his view, the key lies in the realistic long-term strategic planning of resources backed by a comprehensive educative programme designed to produce a climate of opinion prepared to accept the implications inherent in this kind of policy. The inadequacies of the present planning system are analysed and proposals to reform the appropriate aspects of central and local government are put forward.

Throughout, the author displays an encyclopaedic knowledge in the spheres of planning, administration and legislation, but one suspects that he is less at home when dealing with the ecological aspects of land use planning and wildlife conservation. This book is essential reading for conservationists, planners, educationalists and all concerned in any way with influencing or fashioning the environment of tomorrow.

\section{T. STREETER}

\section{Tropical Pastures, edited by W. Davies and C. L. Skidmore. Faber, 50s.}

The editors of this book, one a former director of the Grassland Research Institute, Hurley, the other the Director of the Commonwealth Bureau of Pastures and Field Crops, also of Hurley, have written the first and last of its thirteen chapters - 'Problems of Pasture Improvements' and 'Reflections and the Future' respectively. Each of the remaining eleven is also by a specialist, experienced in some aspect of tropical grassland management or research; two are by veterinarians. With such a sweeping title it is understandable that there should be some gaps, the most notable of these being the lack of emphasis on arid and semi-arid tropics; over half of the authors had most of their experience in the humid tropics.

In a brief mention of the tsetse fly good hope is held out for chemo-therapy as a way of allowing cattle to colonise fly-infested land, but the issues of deciding whether or not to clear land of tsetse, the failures of past schemes and the relation of overgrazing to the spread of tsetse in certain semi-arid areas are not discussed.

Looking to the future, the authors have not, surprisingly, predicted more intensive methodology for pasture production with improved use of legumes and fertilisers. There is a plea for biologists and economists to work as a team, but no mention of sociologists although in many regions social factors are easily as 
important as either technical or economic aspects of pasture improvements.

A stimulating chapter by A. S. Thomas on ecology and human influence raises some important issues for all those interested in studying climax vegetation as a standard against which we may compare other ecosystems. He elaborates the concept that the climax theory has slowed down progress in ecological understanding, and observes that many forest areas regarded as climaxes are proving to be nothing of the sort. The notion that climaxes exhibit the greatest diversity of species is challenged, and various ways in which man modifies ecosystems discussed. There is a revealing comparison of ten general descriptions of the same region written between 1863 and 1962, only two of which, one early and one late, are in recognisable agreement. Thomas concludes that "careful records like those of early explorers could be used for the study of future changes. Such records would be in conformity with the true meaning of ecology - the study of living organisms and their relationships to their surroundings.'

THANE RINEY

\section{Plants of the World Vols I \& II, The Higher Plants, by H. C. D. de Wit. Thames \& Hudson, 4 gns each. \\ European Alpine Flowers in Colour, by T. P. Barneby. Nelson $70 \mathrm{~s}$.}

Mountain Flowers in Colour, by Anthony Huxley. Blandford, 30s.

Wild flowers offer a greater scope for superbly illustrated books than almos $t$ any other subject, and these three take full advantage of the opportunities. $\mathrm{Mr}$ de Wit's, originally published in the Netherlands in 1963, has evidently been specially adapted for British readers, with a paragraph about each family in Britain, either wild or in cultivation; and while these descriptions often read as if the author were better versed in books about wild flowers than about wild flowers in the field, they are certainly a useful feature. The plan is to discuss all the gymnosperms (conifers) and angiosperms (flowering plants) family by family, leaving the lower plants (ferns, fungi, mosses and lichens) to a third volume. The book is therefore valuable as a work of reference as well as for its fine colour and monochrome photographs.

The two books on alpine flowers complement each other admirably, and should both be in the baggage of all flower-loving visitors to the mountains of Europe, although only Mr Huxley's will slip easily into the pocket when you get there. Mr Barneby has taken all the 575 superb colour photographs himself, but he covers only the Alps, and is not fully comprehensive even there. Mr Huxley, on the other hand, has produced an indispensable vade-mecum describing all the flowering plants and ferns of the mountains of western Europe, from the Pyrenees to the Julian Alps and Scandinavia, illustrating over 1200 of them, 884 in colour. So while, if you can only buy one it must be Mr Huxley's, Mr Barneby supplements him so admirably that you might buy his book for your wife while you are about it.

RICHARD FITTER

\section{Handbook of New Guinea Birds, by Austin L. Rand and E. Thomas Gilliard. Weidenfeld \& Nicolson, $£ 66$ s.}

This is an excellent example of the modern type of handbook, as distinct from a field guide, condensing within one cover a great part of what is known about the birds of an area. A vast amount of information is packed into it, though one could wish that the short introductory chapter giving the geographical and climatic background, an account of the composition of the New Guinea avifauna, and a short summary of bird migration and breeding seasons in New Guinea, were a bit 